\title{
Determining fatty acids and halal authentication of sausage
}

\author{
1,2, ${ }^{*}$ Guntarti, A., ${ }^{1,2}$ Ahda, M. and ${ }^{1}$ Kusbandari, A. \\ ${ }^{1}$ Faculty of Pharmacy, Universitas Ahmad Dahlan, Yogyakarta 55164, Indonesia \\ ${ }^{2}$ Ahmad Dahlan Halal Center, Universitas Ahmad Dahlan, Yogyakarta, Prof. Dr. Soepomo, Janturan Road, \\ Warungboto, Yogyakarta 55164, Indonesia
}

\begin{abstract}
Article history:
Received: 21 July 2019

Received in revised form: 19 October 2019

Accepted: 20 October 2019

Available Online: 17

November 2019

\section{Keywords:}

Sausages,

Fatty acids content,

Discriminant analysis
\end{abstract}

\section{DOI:}

https://doi.org/10.26656/fr.2017.4(2).261

\begin{abstract}
Sausages are instant food that requires the halal attention for a Muslim. In general, nonhalal issues are usually associated with pig derivatives. One of the pig derivates is lard that can be analyzed using GC-MS via a transesterification catalyzed with a base catalyst like sodium methoxide $2 \%$. This study indicated that pork sausage has different fatty acids compared with beef sausage. The pork sausage contained the dominant fatty acids such as palmitic acid (37.75\%), myristic acid (22.24\%), oleic acid (25.29\%), and lauric acid $(8.46 \%)$. Whereas, beef sausage has the dominant fatty acids of palmitic acid $(42.31 \%)$, oleic acid $(20.19 \%)$, stearic acid (10.92\%) and myristic acid (7.66\%). The commercial sausages 1, 2, and 3 have similar dominant fatty acids such as palmitic acid, oleic acid, stearic acid, and myristic acid compared with fatty acid types in beef sausage. The discriminant analysis also showed that the beef sausage is separated location from pork sausage and all samples are not containing the pork or lard because they are far away from pork sausage.
\end{abstract}

\section{Introduction}

Food is one of the primary needed by humans because it contains some ingredients that the human body needed. The one ingredient is fat or oil in triglyceride form that can be hydrolyzed into glycerol and fatty acids. The hydrolysis process of triglycerides depends on the chain length and molecular position of the fatty acids (Bauer et al., 2005). Based on triglycerides composition, the different animals will result in the differences in triglycerides composition (Rohman et al., 2012). This evidence can be used as one way for discriminant analysis between halal food and non-halal food. For a Muslim, food consumption is supposed for good or healthy food and also halal foods (Fadzlillah et al., 2011).

In general, non-halal products are the product associated with pig derivatives so a Muslim must be aware and take care to choose the halal product. Either producers or consumers must learn to understand about halal and they ensure the halal certification because it has many advantages in the halal product (Hassan and Awang, 2009). Furthermore, certification halal must be the responsibility of both governments and companies to ensure the products is halal (Khattak et al., 2011). Nakyinsige et al, (2012) stated that the head of the meat industry company must know about the rules of sharia in the production of halal meat. This is because the international market for halal food reaches the US \$ 580 billion per year (Qureshi et al., 2012). On the other hand, there is a big contribution from the halal food industry in the development of society and national economic growth (Bohari et al., 2013).

For detection pork or lard in the product, we can analyze the fats content composed of monoglycerides, diglycerides, triglycerides, fatty acids. The biggest component in lard or pork is triglycerides, which is about 95\% (Gunstone, 2002; Lobb and Chow, 2007). Triglycerides (TAG) are a reaction formed from one molecule of glycerol and three fatty acids and it can be hydrolyzed to produce glycerol and fatty acids again (Figure 1). The differences of TGA contained in pork compared with other meat animals cause they can be grouped if the foods contain pork. The analytical methods developed to analyze lard or other components of pork. Ahda et al. (2016) and also Gutierrez and Perona (2000) analyzed pork based on triglycerides component using HPLC. Furthermore, the FTIR spectroscopy is also used as a pork analysis based on fingerprints of functional group (Guntarti et al., 2015; Guntarti and Seshilia, 2017). Besides that, the discriminant analysis also can be grouped based on fatty 
acid types using KLT and GC-MS (Ismiyarto et al., 2006; Almeida et al., 2006; El-Ghorab et al., 2009; Setiawati and Edward, 2012). This research is aimed to analyze commercial sausage products based on fatty acid contents using GC-MS. This is a way for giving a solution where each sausage producing can cause the hydrolysis of triglycerides in sausage. So, fatty acid analysis can be a solution in halal authentication because it can ensure the discriminant result is only based on fatty acids components, not both mixture between triglycerides and fatty acid components.

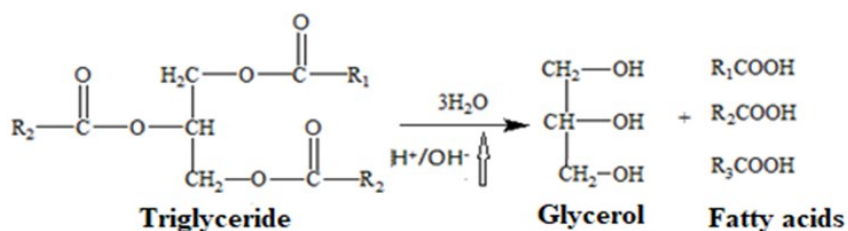

Figure 1. Hydrolysis of triglycerides into fatty acids and glycerol

\section{Materials and methods}

\subsection{Materials}

The used materials: n-hexane, $\mathrm{Na}_{2} \mathrm{SO}_{4}$ anhydride, saturated $\mathrm{NaCl}$, sodium methoxide $2 \%$.

\subsection{The extraction of triglycerides in pork, beef and sausage.}

Samples of meat (pork, beef) sausages were sliced into small pieces, put in a glass beaker, put in an oven at a temperature of $50^{\circ} \mathrm{C}$ until it was melted. Furthermore, the above fat liquid was extracted with n-hexane and then added $\mathrm{Na}_{2} \mathrm{SO}_{4}$ anhydride to bind the water. The fat liquid was evaporated before the transesterification process.

\subsection{Transesterification process of triglycerides of sausages samples}

A total of $20 \mathrm{mg}$ of samples fat was added using 50 $\mathrm{mL}$ of sodium methoxide solution $(\mathrm{NaOH}$ : methanol $2 \%$ $\mathrm{w} / \mathrm{v}$ ) and then heated at $60^{\circ} \mathrm{C}$ for 60 mins. After that, the solution was kept at room temperature and then added the saturated $\mathrm{NaCl}$. The supernatant can be separated using centrifugation method and up layer injected on the GC-MS instrument.

\subsection{Data processing}

Chemometrics analysis of principal component analysis (PCA) using Minitab 16 software. The variables used for discriminant analysis are fatty acid types and relative fatty acid content, in each sausage will be determined.

\section{Results and discussion}

Analysis of fatty acid components in sausage is very important from the difference of carbon atoms length, fatty acids saturation degree, and double bonds position in the chain of fatty acids (Dupuy, 1996). Fatty acids can be classified to become saturated fatty acids, monounsaturated fatty acids, and also polyunsaturated fatty acids (Coltro, 2005). Figure 2 showed a difference in chromatogram profiles of all sausage samples. $100 \%$ pork sausage (red color) appeared to have a different chromatogram profile with $100 \%$ beef sausage (blue color). Commercial sausage samples (yellow color) have similarities with $100 \%$ beef sausage (blue color). The fatty acids in $100 \%$ pork sausage are more than the fatty acids contained in $100 \%$ beef sausage and commercial sausages.

The composition of the sausage samples with values that vary in each fatty acid. Palmitic acid contained in all the sample sausage has the highest percentage. In comparison, $100 \%$ pork sausage containing palmitic acid is lower than $100 \%$ beef sausage and commercial sausage. Oleic acid which is contained in the fifth sample is also very varied. $100 \%$ pork sausage contained the dominant fatty acids such as palmitic acid (37.75\%), myristic acid (22.24\%), oleic acid (25.29\%), and lauric acid $(8.46 \%)$. While $100 \%$ of beef sausage contained the predominant fatty acid such as palmitate acid (42.31\%), oleic acid (20:19\%), stearic acid (10.92\%) and myristic (7.66\%). Commercial sausage 1 contained dominant fatty acids such as palmitic acid (45.99\%), oleic acid $(27.55 \%)$, stearic acid (12.81\%) and myristic acid (4.71\%). Commercial sausage 2 contained dominant fatty acids such as palmitic acid (47.29\%), oleic acid $(38.08 \%)$, stearic acid $(6.10 \%)$, and palmitoleic acid $(2.26 \%)$. Commercial sausage dominant 3 contained dominant fatty acids such as palmitic acid (46.79\%), oleic acid (27.65\%), stearic acid (11.71\%) and myristic acid (5.37\%). The fatty acids contained in beef sausage, pork sausage, and commercial sausages are tabulated in Table 1.

In Table 1, 100\% pork sausage is detected lauric acid on while it's undetected in $100 \%$ beef sausage and commercial sausages. This fact has influenced high temperatures that cause fat damage through hydrolysis reaction and oxidation reaction during the process of derivatization. The process of fat oxidation will occur in the unstable hydroperoxide of long-chain fatty acids become short-chain fatty acids. Hence, the lauric composition in pork sausage is very high. The speed of the oxidation process also depended on the type of fat and storage conditions. There are some undetected fatty acids in the samples at the time of the analysis, so the value of the total fatty acids is lower than the supposed 


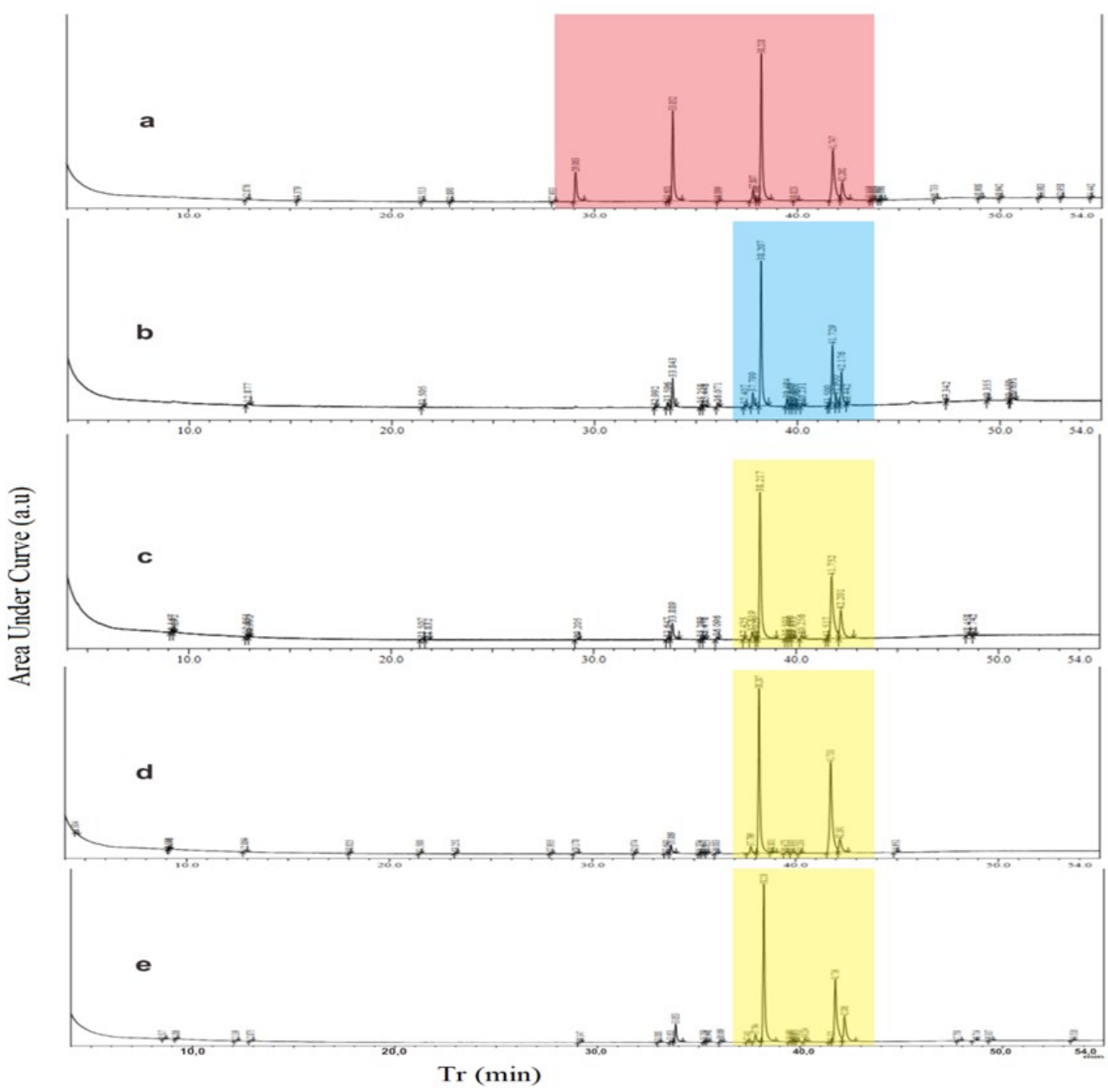

Figure 2. Chromatogram profiles of sausage samples a) 100\% Pork Sausage, b) 100\% Beef sausage, c) Commercial sausage 1, d) Commercial Sausage 2, e) Commercial sausage 3.

Table 1. Composition of fatty acid methyl ester (FAME) in sausage samples

\begin{tabular}{|c|c|c|c|c|c|c|c|c|c|}
\hline \multirow[b]{2}{*}{$\begin{array}{l}\text { Retention } \\
\text { time }\end{array}$} & \multirow[b]{2}{*}{$\begin{array}{c}\text { Chemical } \\
\text { formula }\end{array}$} & \multirow[b]{2}{*}{ Fatty acid name } & \multicolumn{7}{|c|}{ FAME relative $(\%)$} \\
\hline & & & $\begin{array}{c}100 \% \text { pork } \\
\text { sausage }\end{array}$ & $\begin{array}{c}100 \% \text { beef } \\
\text { sausage }\end{array}$ & $\begin{array}{c}\text { Commercial } \\
\text { sausage } 1\end{array}$ & $\begin{array}{c}\text { Commercial } \\
\text { sausage } 2\end{array}$ & $\begin{array}{c}\text { Commercial } \\
\text { sausage } 3\end{array}$ & SI & $\mathrm{BM}$ \\
\hline 29,063 & $\mathrm{C} 12: 0$ & Lauric acid & 8.46 & - & - & - & - & 94 & 200 \\
\hline 33,852 & $\mathrm{C} 14: 0$ & Myristic acid & 22.24 & 7.66 & 4.71 & 2.2 & 5.37 & 96 & 228 \\
\hline 36,071 & $\mathrm{C} 15: 0$ & $\begin{array}{l}\text { Pentadekanoat } \\
\text { acid }\end{array}$ & 0.1 & 1.06 & 0.68 & 0.23 & 0.7 & 84 & 242 \\
\hline 37,807 & C16:1 & Palmitoleic acid & 3.2 & 3.71 & 2.19 & 2.26 & 2.53 & 96 & 254 \\
\hline 38,218 & $\mathrm{C} 16: 0$ & Palmitic acid & 37.75 & 42.31 & 45.99 & 47.29 & 46.79 & 97 & 256 \\
\hline 40.234 & $\mathrm{C} 17: 0$ & $\begin{array}{l}\text { Heptadecanoic } \\
\text { acid }\end{array}$ & 0.15 & 0.97 & 0.9 & 0.3 & 0.95 & 87 & 270 \\
\hline 41.736 & C18:1 & Oleic acid & 25.29 & 20.19 & 27.55 & 38.08 & 27.65 & 95 & 282 \\
\hline 42,202 & $\mathrm{C} 18: 0$ & Stearic acid & 6.56 & 10.92 & 12.81 & 6.1 & 11.71 & 96 & 284 \\
\hline
\end{tabular}

value. $100 \%$ pork sausage contained the highest myristic thing went for the three commercial sausages with a acid compared with other sausage fat which is $22.24 \%$, while the beef fat contained $7.66 \%$ myristic acid, all the three samples of commercial sausage contained $4,71 \%$; $2,20 \%$; and 5,37\% myristic acid respectively. This shows that commercial sausage resembled $100 \%$ beef sausage shown in Table 1.

Differences are also seen in palmitic acid, which is $37.75 \%$ contained in $100 \%$ pork sausage, while $100 \%$ beef sausage has a higher value which is $42.31 \%$, Same value of $45.99 \% ; 47.29 \%$; and $46.79 \%$ respectively, the stearic acid content in $100 \%$ beef sausage is $10.92 \%$ higher than $100 \%$ pork sausage with a content of $6.56 \%$, a different fatty acid composition among samples of $100 \%$ beef sausage and $100 \%$ pork sausages based on the results of GC-MS analysis in which the saturated fatty acid content of $100 \%$ beef sausage is greater than $100 \%$ pork sausage. The identification of the three commercial sausages above has a similar fatty acid content with $100 \%$ beef sausage. This is consistent with 
the results seen in the grouping of PCA as seen in the commercial sausages plot included in the same quadrant with beef sausage.

In addition, the value of Similarity Index (SI) may indicate the accuracy of the data based on the similarity of fragmentation pattern and basic peak (base chromatogram) which referred to the literature of standardized instruments. The greater its SI value, the more accurate the identification of compounds on the MS instrument. Each of the identified compounds can then obtained information about the relative molecular mass using MS spectra. Then, the data of fatty acids content were analyzed using principal component analysis for discriminant and grouped the commercial sausage products and this method more effective and to be easier to conclude that the commercial sausage product is not containing lard or pork. Based on Figure 3, pork sausage and beef sausage are separate in different quadrants. This is a piece of evidence that fatty acid content in both beef sausage and pork sausage is different. The commercial product 2 made is not containing pork or lard or beef. In contrast, both commercial products 1 and 3 showed that both are located in the same quadrant with beef sausage. It can be concluded that both made from beef because they have similar fatty acid contents as beef sausage.

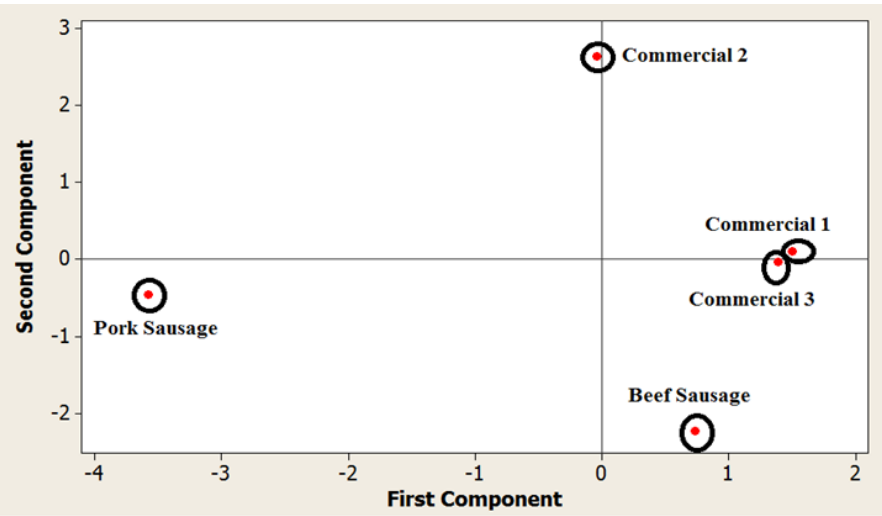

Figure 3. PCA Score Plot of fat from Pork sausage, Beef sausage, Commercial 1, Commercial 2, and Commercial 3, by using fatty acids as a variable.

The results of PCA analysis using Minitab resulted in 8 PCs are presented in Figure 4. Each PC displays eigenvalue, proportion, and cumulative values. Eigenvalue variations can explain the data on each PC and show how much influence a variable on the formation of the characteristics of a matrix (Miller and Miller, 2005). In Figure 4, PC1 with eigenvalue 4.3992 is able to describe $55.5 \%$ of the total original data variables while PC2 with eigenvalue 3.0274 is able to describe $37.80 \%$ of the total original variables. Thus, 2 PCs described the illustration data for discriminant analysis of sausage samples of $92.80 \%$.

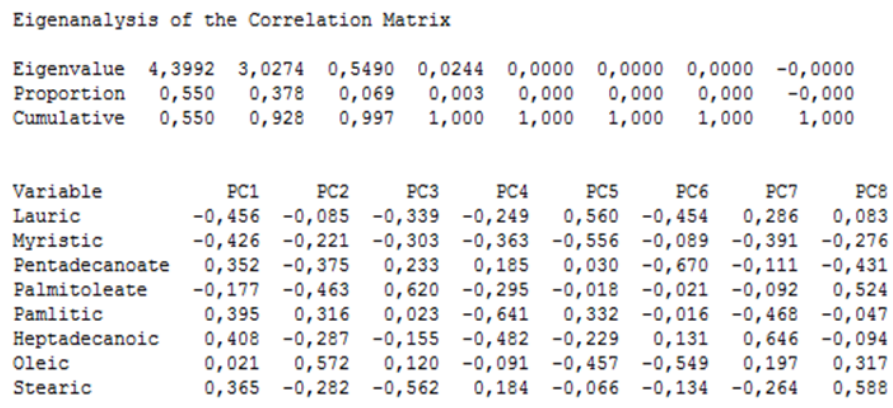

Figure 4. The report of PCA analysis of sausage and some parameters of its Eigenanalysis

\section{Conclusion}

The beef and pork sausages have different fatty acids contents, where pork sausage has palmitic acid (37.75\%), myristic acid (22.24\%), oleic acid (25.29\%), and lauric acid $(8.46 \%)$. Whereas, beef sausage contains palmitic acid (42.31\%), oleic acid (20.19\%), stearic acid $(10.92 \%)$ and myristic acid (7.66\%). The sausage commercials contain fatty acid dominant such as palmitic, oleic, stearic, and myristic where they have similarity fatty acids content like fatty acids of beef. The PCA analysis showed all of the commercial sausages did not contain the pork or lard because they located far away from pork sausage based on its fatty acid content.

\section{Acknowledgement}

We would like to thank for the Grants Higher Education 2015 from the Ministry of Education on fundamentals scheme given in this research.

\section{References}

Ahda, M., Guntarti, A. and Kusbandari, A. (2016). The Discriminant Method between Lard, Virgin Coconut Oil (VCO), Chicken and Beef Fat Based on Triglycerides Composition Using HPLC-UV. Journal of Chemical and Pharmaceutical Research, 8(5), 555-558, ISSN : 0975-7384

Almeida, J.C., Perassolo, M.S., Camargo, J.L., Bragagnolo, N. and Gross, J.L. (2006). Fatty acid composition and cholesterol content of beef and chicken meat in Southern Brazil, Brazilian Journal of Pharmaceutical Sciences, 42(1),109-117. https:// doi.org/10.1590/S1516-93322006000100012

Bauer, E., Jakob, S. and Mosenthin, R. (2005). Principles of physiology of lipid digestion. Asian Australian Journal of Animal Science. 18(2), 282-295. https:// doi.org/10.5713/ajas.2005.282

Bohari, A.M., Hin, C.W. and Fuad, N. (2013). The competitiveness of halal food industry in Malaysia: A SWOT - ICT analysis, GEOGRAFIA Online ${ }^{\mathrm{TM}}$. Malaysia Journal of Society and Space, 9(1), 1-9. 
Coltro, W. (2005). Correlation of animal diet and fatty acid content in young goat meat by gas chromatography and chemometrics. Meat Science, 71(2), 358-63. https://doi.org/10.1016/ j.meatsci.2005.04.016

El-Ghorab, A.H., El-Massry, K.F., El-Hadadd, A.F., Shedied, S.A., Shaheen, M.S. and Gad, A.M. (2009). Chemical Composition and Antiradicals Activity of the Volatile Compounds from Reaction of Cysteine/ Ribose and Beef Fat. World Journal of Dairy and Food Sciences, 4(2), 164-175

Fadzlillah, N.A., Che Man, Y.B. and Jamaludin, M.A. (2011). Halal Food Issue from Islamic and Modern Science Perspective, presented at the 2nd International Conference on Humanities, Historical and Social Sciences. International Proceedings of Economics Development and Research, 17, 159-163

Guntarti, A. and Seshilia. (2017). Application method of Fourier Transform Infrared (FTIR) combined with chemometrics for analysis of rat meat (Rattus diardi) in meatballs beef. Pharmaciana, 7(2), 133-140. https://doi.org/10.12928/pharmaciana.v7i2.4247

Guntarti, A., Martono, S., Yuswanto, A. and Rohman, A. (2015). FTIR Spectroscopy in Combination with Chemometrics for Analysis of Wild Boar Meat in Meatball Formulation. Asian Journal of Biochemistry, 10(4), 165-172.

Gunstone, F.D. (2002). Vegetable Oils in Food Technolgy, Composition, Properties, and Uses. London, United Kingdom: CRC Press.

Hassan, W.M.W. and Awang, K.W. (2009). Halal Food in New Zealand Restaurants: An Exploratory Study. International Journal of Economics and Management, 3(2), 385 - 402

Khattak, J.Z.K., Mir, A., Anwar, Z., Wahedi, H.M., Abbas, G., Khattak, H.Z.K. and Ismatullah, H. (2011). Concept of Halal Food and Biotechnology. Advance Journal of Food Science and Technology, 3 (5), 385-389

Lobb, K. and Chow, C.K. (2007). Fatty Acid Classification and Nomenclature, dalam Chow, C.K., (Ed.) Fatty Acid in Foods and Their Health Implications. 3rd ed. Boca Raton: CRC Press. https://doi.org/10.1201/9781420006902.ch1

Miller, J.N. and Miller, J.C. (2005). Statistic and Chemometrics for Analytical Chemist. 6th ed., p. 89105. Harlow: Pearson Education Limited.

Nakyinsige, K., Che Man, Y.B., Sazili, A.Q., Zulkifli, I. and Fatimah, A.B. (2012). Halal Meat: A Niche Product in the Food Market, presented at the 2nd International Conference on Economics, Trade and Development (IPEDR). International Proceedings of
Economics Development and Research, 36, 167-173

Qureshi, S.S., Jamal, M., Qureshi, M.S., Rauf, M., Syed, B.H., Zulfikar, M. and Chand, N. (2012). A Review of Halal Food with Special Reference to Meat and Its Trade Potential. The Journal of Animal and Plant Sciences, 22(2 Suppl.), 79-83

Rohman, A., Triyana, K., Sismindari and Erwanto, Y. (2012). Differentiation of lard and other animal fats based on triacylglycerols composition and principal component analysis, International Food Research Journal 19(2), 475-479

Setiawati, E. and Edward, F. (2012). Technology Processing of Biodiesel from Used Cooking Oil by Microfiltration and Transesterification Techniques as an Alternative Fuel of Diesel Engine. Jurnal Riset Industri 6(2), 117-127. 